\title{
Sobre Laura Restrepo y el Delirio
}

About Laura Restrepo and Delirium

Fabio Andrés Rodríguez Vásquez

Profesional en Estudios Literarios

Universidad Autónoma de Bucaramanga

frodriguez73@unab.edu.co

fabioandresrodriguez@gmail.com

Artículo recibido el 20 de abril 2015

Aprobado el 04 de mayo del 2015 ‥

\section{Resumen}

El siguiente artículo retoma los planteamientos principales de la investigación titulada: Sobre Laura Restrepo y Delirio. Investigación que se desarrolló en 2014 en la Universidad Autónoma de Bucaramanga y que corresponde a un acercamiento crítico literario a la novela Delirio de la escritora colombiana con la cual ganó el prestigioso premio Alfaguara de novela. En esta investigación se utiliza como herramienta metodológica el análisis de discurso

Palabras claves: Novela, Análisis del discurso, Violencia, Escritura

\begin{abstract}
The following article takes up the main approaches of the research entitled: About Laura Restrepo and Delirium. This research was developed in 2014 at the Universidad Autónoma de Bucaramanga and it corresponds to a literary and critical approach to Delirium a novel written by the Colombian writer. It won the prestigious Alfaguara prize. In this research, we use the Critical Analysis of Discourse as a method .
\end{abstract}

Key words: Novel, Discourse Analysis, Violence, Writing

\section{Introducción}


Laura Restrepo, periodista de oficio, filósofa y escritora de profesión, militó durante cuatro años en el Partido Socialista de los Trabajadores (PST) de Argentina. En Colombia jugó un rol de importancia en la evolución del proceso de paz como facilitadora en la negociación entre el gobierno y el M-19 en 1986. De aquella experiencia nace la novela Historia de una traición (1989) - que posteriormente fuera renombrada Historia de un entusiasmo - su primer intento por retratar, a través de la novela, su visión de la realidad política en Colombia..

Tras su salida del país continuó su producción escrita dentro de géneros como el ensayo, la novela corta y los cuentos infantiles. De manera simultánea, siguió desarrollando la labor periodística en publicaciones de opinión como la Revista Semana (Colombia) y La Jornada (México).

La escritora publica en 2004 su novela Delirio, un relato de hechos de la primera mitad de la década de los años ochenta que evidencia cómo el narcotráfico inundó la sociedad colombiana en todos sus estratos y en todas las prácticas sociales. A través de esta obra Restrepo relata la forma como colombianos en todos los estratos sociales llegaron a ser beneficiarios, en ceguera monumental, de las riquezas provenientes del conflicto desatado por la guerra de las drogas que aún hoy aflige al país.

En Delirio, Restrepo hace hincapié en el pacto de silencio que muchos colombianos firmaron frente a Pablo Escobar a cambio del dinero del narcotráfico. Este pacto, tácito y silencioso, es el telón de fondo que usa Restrepo para dibujar a la sociedad colombiana de mediados de 1980. Quizá el delirio de Agustina, protagonista de la novela, que la sumerge en el olvido, es el reflejo de las creencias de la sociedad que Restrepo tiene en su imaginario, una sociedad que vivía en constante dualidad: la hipocresía de las clases medias y altas, beneficiadas por el ejercicio placentero de la recepción del dinero fácil, y el rechazo de las prácticas narcotraficantes que tenían al país sumido en un conflicto que desafortunadamente se mantiene vigente.

En esta, la obra número once de su carrera y su sexta novela publicada, Restrepo hace un viaje retrospectivo por la Colombia de la primera mitad de la década del ochenta a través del lente de personajes muy variados, principalmente Agustina, quien sirve como vehículo con el que busca demostrar la relación entre el caos externo y los mecanismos mentales que usa el individuo para vivir en medio de una realidad caótica.

Restrepo sitúa la novela dentro de un contexto social conocido: la sociedad bogotana de fines del siglo XX, afligida por la violencia y el narcotráfico, creando un escenario ideal para articular reflexiones de la sociedad colombiana contemporánea. Al hacerlo, Restrepo reúne diversos tipos de discursos característicos de esa sociedad y procede a integrarlos para trazar puntos de identidad y diferencias de las clases sociales con el 
fin de demostrar las relaciones de poder que existían (y aún persisten) entre la clase aristocrática y las clases emergentes.

\section{Metodología}

El método que se usó en esta investigación para reflexionar en torno a la temática que presenta Delirio es el del Análisis de discurso.

\section{Análisis de la narración}

Delirio es una narración fluida que se desarrolla en los hombros de los personajes a través de varios momentos como la infancia de Agustina, la vida familiar de los Londoño. En este apartado de la investigación, se estudian el tiempo y la estructura a partir de los postulados narratológicos de Genette (1989).

\section{Tiempo y estructura}

Delirio, a diferencia de otras novelas, no está dividida en capítulos, sino que la historia central y las historias subyacentes se narran de manera paralela, en escenarios y espacios temporalmente diferentes. Aunque cabe aclarar que dichos marcos temporales no se hacen explícitos en el texto ni tampoco existen marcos textuales que señalen el comienzo de las otras narraciones, pues el lenguaje no cambia drásticamente al cambiar la voz narrativa.

Delirio está escrita en contravía de las normas estándar de la ortografía del español moderno: las indicaciones externas como, por ejemplo, la puntuación y el uso de las letras mayúsculas, parecen seguir una lógica narrativa exclusiva para los propósitos narrativos de la escritora y pueden, en ocasiones, resultar confusas para el lector:

Fue a mi regreso de un viaje corto, sólo cuatro días por cosas de trabajo, dice Aguilar y asegura que al partir la dejó bien, Cuando me fui no le pasaba nada raro, o al menos nada fuera de lo habitual, ciertamente nada que anunciara lo que iba a sucederle durante mi ausencia. (Restrepo, 2004: 11)

En este ejemplo se ilustra cómo Restrepo hace uso de letras mayúsculas después de una coma, y cómo las frases directas no son marcadas por ninguna indicación externa. Los narradores se expresan de la misma manera. Esta cita muestra en el nivel oracional una mezcla de voces entre el narrador central omnisciente y los personajes, Esta es la técnica narrativa usada frecuentemente por la autora en el discurso narrativo en Delirio. Se puede concluir, entonces, que la autora escribe su historia a través de un estilo experimental e innovador.

Para comprender cómo funciona la trama novelesca en Delirio se debe entender en qué lugar coexisten las diferentes narraciones, dónde se complementan y dónde forman la trama central de la novela. 
Delirio consta de cuatro historias engarzadas entre sí, sesenta y seis fragmentos, y cuatro voces narrativas distintas: la historia de Agustina, la historia de Midas McAlister, lavador de dólares que reside en Bogotá en la década de los años ochenta; la historia de Aguilar, el novio de clase media de Agustina; y la historia de Nicolás Portulinus, difunto abuelo de Agustina.

En conjunto estas historias forman parte de un objetivo superior: el intento narrativo de explicar la causa de la locura de Agustina. La historia de Portulinus funciona literariamente como una representación de la herencia familiar de Agustina: se alude a que el delirio mental de Agustina sea, parcialmente, una consecuencia de condiciones genéticas y no sólo psicosociales. La narración muestra que Portulinus, al igual que Agustina, sufre de una enfermedad mental.

Además de narrar el delirio y la búsqueda de la causa de la enfermedad de Agustina, el discurso de Aguilar, Agustina y Midas funcionan como puentes que ayudan al lector a transportarse entre los diferentes códigos sociales vigentes en la clase aristocrática bogotana y en la clase emergente de los jefes del narcotráfico de la época.

En estas cuatro narraciones se incluye además una presentación literaria de las apariencias (el qué dirán) representada principalmente por la familia Londoño.

Las narraciones de Midas y Aguilar incorporan también una presentación literaria de la situación sociopolítica y económica de la realidad colombiana contemporánea. La narración personal de Agustina presenta al mismo tiempo la historia de su infancia, poniendo énfasis especial en las relaciones familiares.

A medida que avanza la narración, Restrepo agrega elementos que pueden conducir al lector a pensar que la enfermedad mental de Agustina puede ser una consecuencia del mal funcionamiento de las relaciones sociales y culturales dentro de la clase social a la que pertenece la protagonista. A mi entender, las cuatro narraciones complementan la imagen de la protagonista Agustina y, sobre todo, muestran la causa de su enfermedad. Aunque, paralelamente, reflejan la situación social y política colombiana.

\section{Análisis del discurso}

Como se mencionó en la definición del marco teórico del proyecto de investigación, para realizar el análisis de la novela se usó como guía el trabajo desarrollado por el teórico Teun A. Van Dijk, tomando como base principal Critical Discourse Analysis (1999) y su trabajo en lo relacionado con discurso, cognición y sociedad (1997) y discurso y dominación (2005), con el fin de explorar la relación entre los personajes y la influencia, o la ausencia de ella en el desarrollo de los eventos relatados en la novela.

\section{El discurso violento}


El tema de las violencias está presente, de varias maneras, en el discurso público colombiano y se articula constantemente en los medios de comunicación y a través de publicaciones críticas y literarias.

En la novela Delirio, el discurso de la violencia se introduce y desarrolla como un fenómeno cotidiano, sin ser explicado de ninguna manera por la narradora. Comentaré algunos episodios donde la violencia es enfatizada por los narradores, como ocurre en sus descripciones de Bogotá. A mi entender, la descripción de la ciudad que aparece en Delirio refleja literariamente la violencia sociopolítica que vivía el país en los años ochenta:

Mientras caminábamos desde el centro por la carrera Séptima a la medianoche, es decir plena happy hour de raponazos y puñaladas, ella me organizaba en la cabeza un turbante a lo Greta Garbo, unas orejas de Conejo de la Suerte con los dos extremos de la bufanda, un trapo palestino a lo Yasser Arafat, al tiempo que yo, tenso y vigilante, iba pendiente de cada bulto que se agitaba en la calle solitaria. (Restrepo, 2004, p.54, 55)

Se observa aquí que la narradora describe un lugar donde actos violentos aterrorizan a los habitantes de la ciudad. No obstante, el uso del término inglés happy hour crea una imagen irónica cuando se combina con las palabras raponazos y puñaladas. Hay que notar que el tiempo novelesco coincide con el tiempo real de la guerra contra el Estado declarada por Pablo Escobar. Aunque las acciones violentas no son realizadas únicamente por tal persona real, no cabe duda de que buena parte de la violencia desprende de sus decisiones y acciones, como lo revela el empleo frecuente de las bombas detonadas para aterrorizar al país.

Tampoco hay que olvidar que Escobar declaró la guerra especialmente contra las clases altas pues las consideraba sinónimo de la clase política tradicional que tan fuertemente lo criticara cuando ocupó un cargo en el Congreso. En Delirio, se narra por ejemplo una escena donde Escobar hace estallar una bomba en el restaurante L’Esplanade, situado en una de las zonas de mayor prestigio de la ciudad de Bogotá.

Otros ejemplos útiles para ilustrar cómo el discurso de la violencia está presente en la novela son los relativos al secuestro. Hacia la mitad de la década de los ochenta, era frecuente el secuestro como método de extorsión. No es un tema importante en Delirio, pero sí está presente, por ejemplo, cuando el narrador informa que incluso la Araña Salazar, importante miembro de una organización delictiva, “andaba paranoico con los secuestros" (Restrepo, 2004: 42).

En resumen, Restrepo crea en Delirio unos personajes de ficción que habitan un mundo donde la violencia histórica y real se mezcla con el caos interno de la vida de los personajes. En otras palabras: la violencia histórica es literaturizada por la autora quien, a través de sus narradores, incorpora ideas de la realidad histórica contemporánea, junto al relato de violencia, combinando así los dos tipos de presentación 
literaria en su novela.

\section{Resultados}

Esta investigación arroja como resultados principales, los siguientes: la construcción de un marco de referencia y los planteamientos teóricos base para el desarrollo del análisis de esta novela de Laura Restrepo.

A través del análisis del discurso de los personajes y el tipo de narrador que Restrepo escogió para presentar a cada uno, se pudo verificar que el discurso de la novela forma parte de los discursos que circulan en la sociedad del momento histórico retratado.

A la luz de las teorías de Gérard Genette examiné la estructura narratológica de la obra. Hice un análisis de la estructura externa e interna de la novela, poniendo énfasis especial en los elementos narrativos del tiempo, la voz y la focalización.

Presenté la historia o la trama de la novela para luego comprobar que, a nivel de la estructura interna, Delirio tiene múltiples narradores: Agustina, Aguilar, Midas McAlister y un narrador central extradiegéticoheterodiegético. Encontré que las distintas narraciones tienen en común que el narrador extradiegéticoheterodiegético se entromete en las narraciones, quizá revelando el tono periodístico que quizá de manera inconsciente agrega Restrepo para novelizar la realidad colombiana contemporánea.

Se pudo constatar que todos los narradores tienden a hablar de manera semejante, lo único que distingue el lenguaje en las cuatro historias contadas, es el léxico elegido por el narrador (i.e. los vocablos que se usan para referirse a los personajes femeninos). Comprobé que las micronarraciones de Midas, Agustina y Aguilar también presentan huellas de oralidad. Al respecto, constaté que la ortografía usada en la novela contribuye a conferir una cualidad oral a la novela: la autora elige usar reglas ortográficas experimentales que no siguen las normas estándar de la ortografía del español moderno para hacer que el lenguaje escrito imite la lengua hablada.

Se pasó a explorar cómo el discurso narrativo de la novela ilustra o no las relaciones existentes entre el tipo del lenguaje usado por los personajes y el poder patriarcal que éstos despliegan en el relato y se concluyó que hay, en efecto, una relación entre el poder patriarcal y el lenguaje que usan los personajes masculinos.

\section{Conclusiones}

Esta investigación realizó el análisis a la novela Delirio de Laura Restrepo a la luz de postulados de la narratología Gérard Genette de historia, relato, tiempo, voz y focalización como en los conceptos del ACD 
(Análisis Crítico del Discurso) desarrollados por el holandés Teun A. Van Dijk (2009). También se estudió cómo el lenguaje de la novela está relacionado tanto con el concepto de nominalización como con el concepto de poder y se pudo determinar que en ella hay una íntima relación entre la trama, la historia (discurso historiográfico) y realidades colombianas de la época.

Así mismo, se pudo constatar que el discurso de la novela forma parte de los discursos que circulan en la sociedad actual y se analizaron los conceptos discurso y poder (y la relación entre tales conceptos) en Delirio conforme a la perspectiva de Van Dijk.

Con Delirio, se demuestra que Laura Restrepo hace parte de un grupo de escritores que buscan crear una literatura realista basada en la condición social, política y económica de la Colombia de su época, que, entre otras cosas, permite afirmar que esta novela hace parte de la literatura del narcotráfico, desarrollada en Colombia como respuesta a la realidad de un país afligido por el comercio de drogas ilegales, la corrupción y la violencia.

Este análisis permitió verificar el conocimiento y concepción de la sociedad colombiana de la época a través de los personajes en la novela y evidenciar que los discursos corresponden a los de la realidad del país en la época relatada.

El estudio del discurso permitió además verificar que la novela participa de los discursos políticos y culturales que aún circulan en la sociedad colombiana, como el discurso de la violencia presentado literariamente de distintas maneras a lo largo de la novela.

Concluyo pues que Delirio opera con un comentario del discurso de la violencia en Colombia, pero que no se queda ahí pues intenta analizar los efectos psicológicos de la violencia sobre las personas. Presenta un discurso popular, en el que las habladurías o rumores colectivos se incorporan al texto, pero aún más importante, el discurso es empleado como instrumento que sirve para establecer jerarquías sociales. Literariamente se recrea una imagen de Pablo Escobar que incorpora ideas populares sobre su persona e idealiza su personalidad. Al crear relatos sobre los paramilitares, Laura Restrepo incluye en su novela estereotipos colectivos, estableciendo así una estrecha relación entre los paramilitares y las familias ricas de Bogotá y Medellín. Delirio, como quedó comentado, funciona también como una mirada al discurso patriarcal vigente en la sociedad y, a su vez, critica el dominio patriarcal en el mundo ficticio de la novela. El personaje Agustina Londoño simboliza una resistencia femenina hacia los valores patriarcales, las apariencias, expectativas y las normas de conducta de las clases altas bogotanas.

Así mismo, resulta válido entender a Delirio como una interpretación de la realidad de la sociedad pues su discurso tiene como base la realidad histórica y social contemporánea de Colombia.

Es evidente que la violencia ha impactado de manera directa en la creación de un imaginario que 
abunda en la literatura que ha buscado abordar dicha problemática desde diversos ángulos y, con Delirio, Laura Restrepo invita al lector a acompañarla en una narración llena de mensajes implícitos que de cierta forma definieron a la sociedad colombiana de mediados de la década de los ochenta.

Con Delirio, Restrepo ahonda en la violencia acudiendo a personajes de diversos orígenes quienes se ven afectados directa o indirectamente por el narcotráfico y sus repercusiones sociales y económicas.

Delirio es entonces una lupa que se encarga de explorar terrenos que se extienden más allá de los propios de la violencia generada por el narcotráfico en la sociedad como colectivo, pues examina su impacto psicológico y social en sus integrantes como individuos.

Por último, se comprueba la concordancia entre la trama y la historia real del país en varios niveles: primero, los discursos que circulan en la sociedad se incorporan al mundo ficticio de la novela y, además, funcionan como retratos mediatizados por los narradores, convirtiéndose así en áreas limitadas del conocimiento sociopolítico de Colombia; segundo, el lenguaje empleado en la novela, tanto de los personajes como del narrador omnisciente, demuestra tanto los rasgos del discurso para ejercer influencia como las relaciones de poder en la sociedad colombiana; y tercero, la novela intenta desvelar los mecanismos sociales en la sociedad bogotana, en particular, las relaciones sociales de poder entre las clases altas bogotanas y las nuevas clases emergentes de jefes del narcotráfico.

\section{Referencias}

Genette, G. (1989). Figuras III. Traducción de Carlos Manzano. Barcelona: Editorial Lumen.

Restrepo, L. (2004). Delirio. Bogotá: Ediciones Alfaguara. (1989). Historia de una traición. Madrid: IEPALA Editorial.

Van Dijk. T. (2009). Discurso y poder. Barcelona: Editorial Gedisa S.A. (2005). "Discurso, conocimiento e ideología”. En: Cuadernos de Información y Comunicación, No. 10, pp. 285-318. Madrid: Departamento de Periodismo III de la Facultad de Ciencias de la Información Universidad Complutense de Madrid (1999). "El análisis crítico del discurso". En: Anthropos (Barcelona), pp. 23-36. Recuperado el 1

de noviembre de 2014, en la URL: http://www.discursos.org/oldarticles /El\%20an\%E1lisis\%20cr\%EDtico\%20del\%20discurso.pdf (1997). “Discurso, cognición y sociedad”. En: Signos 8 (22), pp. 66-74 
Artículo arbitrado por María Florencia Donadi. Doctoranda en Letras y Licenciada en Letras Modernas Universidad Nacional de Córdoba - Argentina. Becaria CONICET y Miembro del Centro de

Investigaciones María Saleme de Burnichon Facultad Filosofía y Humanidades (CIFFyH) de la Facultad de Filosofía y Humanidades. Universidad Nacional de Córdoba 